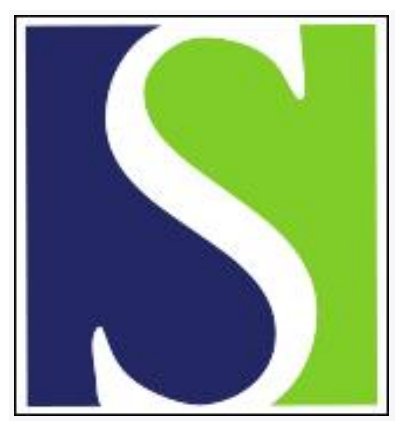

Scand J Work Environ Health 2001;27(6):381-387

https://doi.org/10.5271/sjweh.630

Issue date: Dec 2001

Incidence of musculoskeletal disorders among newly employed manufacturing workers

by Häkkänen M, Viikari-Juntura E, Martikainen R

Affiliation: Finnish Institute of Occupational Health, Musculoskeletal Research Unit, Topeliuksenkatu 41a A, FIN-00250 Helsinki, Finland. marketta.hakkanen@occuphealth.fi

The following articles refer to this text: 2003;29(5):396-405;

2015;41(3):234-246

Key terms: assembly work; induction time; low back; manufacturing worker; MSD; musculoskeletal disorder; neck; physical workload; shoulder; sick leave; survival; upper limb

This article in PubMed: www.ncbi.nlm.nih.gov/pubmed/11800325 


\title{
Incidence of musculoskeletal disorders among newly employed manufacturing workers
}

\author{
by Marketta Häkkänen, MSc, ${ }^{1}$ Eira Viikari-Juntura, DMedSci, ${ }^{1}$ Rami Martikainen, $M S c^{2}$
}

\begin{abstract}
Häkkänen M, Viikari-Juntura E, Martikainen R. Incidence of musculoskeletal disorders among newly employed manufacturing workers. Scand J Work Environ Health 2001;27(6):381-387.
\end{abstract}

\begin{abstract}
Objectives The incidence of upper-limb, neck-shoulder, and low-back disorders and their induction times were investigated among new workers in tasks with various physical workloads.

Methods New trailer assemblers ( $=364)$ were followed prospectively for 45 months — the workers' health status via medical records and exposure to physical workload factors via job titles, walk-throughs, task descriptions, and some direct measurements. The incidence rate of first sick leave due to such disorders was calculated for different workload groups. The proportion of workers surviving without musculoskeletal disorders was estimated by the Kaplan-Maier product-limit estimator, and the effect of the exposure on the risk of incident disorders was estimated with the Cox proportional hazards model.

Results The highest annual incidences were observed for strenuous tasks, the incidence rate for men being 16.8 per 100 person-years [95\% confidence interval (95\% CI) 8.0-30.9] for upper-limb disorders in strenuous tasks and 6.1 (95\% CI 2.0-14.1) in nonstrenuous tasks and that for women being 32.0 (95\% CI 11.7-69.7) and 9.9 (95\% CI 0.2-54.9), respectively. The men's risk of contracting an upper-limb or neck-shoulder disorder in strenuous tasks was about threefold [hazard ratio (HR) 3.2 (95\% CI 1.1-9.4) for upper-limb disorders and 2.7 (95\% CI 0.9-8.1) for neck-shoulder disorders] that of nonstrenuous tasks, whereas workload seemed not to affect low-back disorders. The workers first sought medical advice for their disorders typically some months after employment began.

Conclusions Newly employed workers in hand-intensive tasks have a high risk of upper-limb and neckshoulder disorders. An etiologic role for activities involving high force demands in upper-limb and neckshoulder disorders is possible.
\end{abstract}

Key terms assembly work, induction time, low back, neck and shoulder, physical workload, sick leave, survival, upper limb.

Musculoskeletal disorders are a serious concern in several occupations. Various physical load factors have been discussed in relation to upper-limb, neck and shoulder, and low-back disorders. Most data on physical workload factors are based on cross-sectional studies. Prospective studies comparing incidence rates among populations with different exposures are rare, and such studies on upper-limb disorders are almost nonexistent (1).

Decisions on the compensation of musculoskeletal disorders are based on the probability of causality between the exposure factor and disorder. In addition to knowledge of the magnitude of risk based on prospec- tive studies, we need information concerning how long exposure should be for the onset of the disease. Follow-up studies on different occupational groups have shown that the first musculoskeletal disorders occur in general within 3-6 months after the beginning of employment $(2,3)$. In light manual work the median time period for the first occurrence of neck and shoulder disorders was about 6 months (4). There are, however, very few data on such induction times.

The aim of this study was to investigate the incidence rates for upper-limb, neck and shoulder, and lowback disorders among newly employed workers in tasks 
with various physical workloads. Another aim was to explore the induction times of the disorders and the durations of the sick leaves in tasks with different physical loads.

\section{Subjects and methods}

\section{Study design}

We carried out a longitudinal study in a dynamic population of assembly workers in a Finnish medium-sized trailer assembly plant from 1 January 1987 to 30 September 1990. All workers starting their employment during the follow-up were included in the study. Their health status and sick leaves were followed via medical records, and exposure to physical workload factors was assessed through the use of job titles, walk-throughs, task descriptions, and some direct measurements.

\section{Subjects}

The study population consisted of 364 blue-collar workers who entered the population during the follow-up. Because of rapid economic growth in the country, there was an increase in the production of trailers and a need for new workers. These new workers consisted of 309 male [mean age 25.6 (SD 7.5) years] and 55 female [mean age 29.2 (SD 7.9) years] assemblers. As a rule the workers had not worked earlier in assembly work, although no systematic data collection of work history was done. The follow-up time for each worker was defined as the time from the beginning of employment until sick leave due to a disorder under study $(\mathrm{N}=79)$, termination of employment $(\mathrm{N}=238)$, change of workload category $(\mathrm{N}=11)$, or end of the follow-up of the study $(\mathrm{N}=31)$. The follow-up was also terminated if a worker had a sick leave exceeding 30 days $(\mathrm{N}=5)$. The limit of 30 days was selected on the basis that the typical duration of a Finnish summer vacation could be up to 30 days; an absence exceeding this limit would have blurred the concept of "new worker". Table 1 presents the accumulation of exposure time for the workers during the follow-up period.

\section{Assessment of exposure}

The trailer assembly factory consisted of seven departments in which parts of trailers, such as walls, roofs, floors, and furniture, were made. The parts for the furniture were made in the mechanization department from wooden materials. Some tasks were repetitive for the hand and wrist and involved static postures of the neck. The walls of the trailers were built in the element construction department where the workers frequently had to lift heavy loads and to reach far. The tasks in the departments of furniture assembly and fixing were loading for the upper limbs due to the frequent driving of screws and drilling with pneumatic hand tools, often with high force demands. A pistol-type driver was predominantly used, and ulnarly deviated wrist postures were common, especially when the workers had to reach far. The tasks in the final assembly, inspection, and transportation department were physically less strenuous, including, for example, forklift driving and finishing. Based on walk-throughs in the departments by a researcher $(\mathrm{MH})$, task descriptions, and some direct measurements, the tasks of the departments could be classified into two categories according to exposure to physical load factors for different body regions. For the upper limbs the presence of the following factors was checked: high repetition for $>2$ hours per day, forceful exertion for $>2$ hours per day, and frequent wrist bending. For the neck the factors assessed were neck forward flexion for $>1$ hour per day, hands above shoulders for $>1$ hour per day, and static posture for $>2$ hours per day. For the low back the presence of multiple lifting, trunk forward flexed for $>1$ hour per day, and vehicle transportation for $>2$ hours per day was assessed. The presence of at least two physical load factors for a body region was required for the classification of tasks of a department to fall in the high-exposure category regarding the body region in question. The assessment of the total exposure resulted in categorizing the mechanization, element construction, furniture assembly, and

Table 1. Accumulation of person-years in trailer assembly by gender, age, and workload ( $N=364)$.

\begin{tabular}{|c|c|c|c|c|c|c|c|c|c|c|c|c|}
\hline \multirow{3}{*}{$\begin{array}{l}\text { Age group } \\
\text { (years) }\end{array}$} & \multicolumn{4}{|c|}{ Low workload } & \multicolumn{4}{|c|}{ High workload } & \multicolumn{4}{|c|}{ All workloads } \\
\hline & \multicolumn{2}{|l|}{ Men } & \multicolumn{2}{|c|}{ Women } & \multicolumn{2}{|l|}{ Men } & \multicolumn{2}{|c|}{ Women } & \multicolumn{2}{|l|}{ Men } & \multicolumn{2}{|c|}{ Women } \\
\hline & Person-years & S $\%$ & Person-years & s $\%$ & Person-years & $\%$ & Person-years & $\%$ & Person-years & $\%$ & Person-years & $\%$ \\
\hline$<25$ years & 34.1 & 41.3 & 1.9 & 18.6 & 33.6 & 56.4 & 4.8 & 25.7 & 67.7 & 47.6 & 6.7 & 23.1 \\
\hline $\begin{array}{c}25-34 \text { years } \\
>34 \text { years }\end{array}$ & $\begin{array}{l}31.8 \\
16.6\end{array}$ & $\begin{array}{l}38.6 \\
20.1\end{array}$ & $\begin{array}{l}3.1 \\
5.2\end{array}$ & $\begin{array}{l}30.4 \\
51.0\end{array}$ & $\begin{array}{r}18.7 \\
7.3\end{array}$ & $\begin{array}{l}31.4 \\
12.2\end{array}$ & $\begin{array}{l}9.5 \\
4.4\end{array}$ & $\begin{array}{l}50.8 \\
23.5\end{array}$ & $\begin{array}{l}50.5 \\
23.9\end{array}$ & $\begin{array}{l}35.5 \\
16.8\end{array}$ & $\begin{array}{r}12.6 \\
9.7\end{array}$ & $\begin{array}{l}43.5 \\
33.4\end{array}$ \\
\hline All & 82.5 & 100.0 & 10.2 & 100.0 & 59.6 & 100.0 & 18.7 & 100.0 & 142.1 & 100.0 & 29.0 & 100.0 \\
\hline
\end{tabular}


furniture fixing departments as strenuous for the musculoskeletal organs. In these departments the tasks were classified into the high-load category for all body regions. The tasks in the final assembly, final inspection, and transportation departments were considered less strenuous for the musculoskeletal organs. A detailed description of the classification of the tasks into those with high and low load has been presented in another paper (5).

Although the production of trailers increased during the study period, the production rate per worker was fairly stable throughout the follow-up. Data on the exposure time of each worker were collected from the employer's records. The information included dates of the beginning and termination of employment in different departments for all periods of employment during the follow-up.

\section{Assessment of outcome}

The trailer assembly factory had an occupational health unit of its own with an occupational health physician and an occupational health nurse. The occupational health services consisted of preventive activities and primary medical care. In case of sick leave, a blue-collar worker had to present a medical certificate from the first day of absence on, whereas this was not the case for the white-collar workers for short sick leaves $(<4$ days). For this reason, and because of their small number, white-collar workers were excluded from the study. The diagnoses and the number of sick leave days were registered in the medical files of the company.

Before being permanently employed in the factory, workers were employed on probation for 4 months. In the beginning of this time the worker underwent a medical examination that included questions on previous diseases and symptoms. All the workers were free of musculoskeletal disorders at the onset of the study.

The beginning and ending dates, as well as the diagnoses of sick leaves were obtained from the medical files. Musculoskeletal disorders, all diagnosed by the same physician, were classified into the following four categories (6): (i) tenosynovitis or peritendinitis in the wrist or forearm, epicondylitis, and other soft-tissue musculoskeletal disorders in the wrist, forearm, or elbow region, (ii) neck and shoulder disorders, (iii) lowback disorders, and (iv) other musculoskeletal disorders.

\section{Statistical analysis}

To define the risk period for the incidence of upper-limb, neck and shoulder, and low-back disorders, we calculated the time from the beginning of employment to the date of the beginning of the first sick leave due to any of the aforementioned musculoskeletal disorders. If a worker never had a sick leave due to a musculoskeletal disorder, the time was calculated until the end of his or her follow-up. The incidence rate of the first occurrence of a upper-limb, neck or shoulder, or low-back disorder was calculated by dividing the number of new cases of these disorders by the total time at risk for all workers in the pertinent exposure group. Due to common risk factors for the disorders under study, the occurrence of any other musculoskeletal disorder than that of interest was considered to be a competing risk; accordingly a worker with such an event was censored.

The proportion of the workers surviving without musculoskeletal disorders was estimated by the KaplanMaier product-limit estimator for both workload groups for the men and the women separately (7). Peto \& Peto's Wilcoxon test was used to assess the homogeneity of survival curves between the exposure groups (8). The difference was tested also at 6 and 12 months. The first check point was fixed at 2 months from the end of the probation period, and the second was chosen as the end of the first year of employment on the basis of the fact that we had a dynamic cohort with a high turnover rate. Furthermore, we hypothesized that the effects of the physical load factors were short-term by nature. The Cox proportional hazards model was used to estimate the effect of the workload (high versus low) on the incident disorders adjusted for age. Unadjusted estimates were computed for the women due to their small number.

\section{Results}

One-fifth $(\mathrm{N}=79)$ of all the workers had sick leaves due to musculoskeletal disorders during the follow-up. For $28 \%(\mathrm{~N}=22)$ of these workers the first sick leave was due to an upper-limb disorder: nine had tenosynovitis or peritendinitis in the wrist or forearm, seven had epicondylitis, and six had some other soft-tissue musculoskeletal disorder in the wrist, forearm, or elbow region. Neck or shoulder disorder was the first cause of absence for $30 \%(\mathrm{~N}=24)$ of the workers, and low-back disorder was first for $42 \%(\mathrm{~N}=33)$.

Among the men the incidence rates for the first occurrence of a musculoskeletal disorder were higher for those in the high workload group than for those in the low workload group (table 2). The largest difference between the groups was observed in the rate of upperlimb disorders, which, in the high workload group, was almost threefold that of the low workload group. Respectively, the rate of neck and shoulder disorders was over twofold, and the rate of low-back disorders was 1.6-fold among those with high a workload. Among the women the incidence rates were generally higher than among the men. Concerning the upper-limb disorders, 
Table 2. Incidence rates for the first occurrence of musculoskeletal disorders by gender and workload among the new trailer assembly workers. $(95 \% \mathrm{Cl}=95 \%$ confidence interval)

\begin{tabular}{|c|c|c|c|c|c|c|c|c|}
\hline \multirow[t]{3}{*}{ Region of disorder } & \multicolumn{4}{|c|}{ Men } & \multicolumn{4}{|c|}{ Women } \\
\hline & \multicolumn{2}{|c|}{$\begin{array}{l}\text { Low workload } \\
\text { (82.5 person-years) }\end{array}$} & \multicolumn{2}{|c|}{$\begin{array}{c}\text { High workload } \\
\text { (59.6 person-years) }\end{array}$} & \multicolumn{2}{|c|}{$\begin{array}{l}\text { Low workload } \\
\text { (10.2 person-years) }\end{array}$} & \multicolumn{2}{|c|}{$\begin{array}{l}\text { High workload } \\
\text { (18.7 person-years) }\end{array}$} \\
\hline & Incidence rate ${ }^{a}$ & $95 \% \mathrm{Cl}$ & Incidence rate ${ }^{a}$ & $95 \% \mathrm{Cl}$ & Incidence rate ${ }^{\mathrm{a}}$ & $95 \% \mathrm{Cl}$ & Incidence rate ${ }^{\mathrm{a}}$ & $95 \% \mathrm{Cl}$ \\
\hline Upper limb & 6.1 & $2.0-14.1$ & 16.8 & $8.0-30.9$ & 9.9 & $0.2-54.9$ & 32.0 & $11.7-69.7$ \\
\hline Neck or shoulder & 6.1 & $2.0-14.1$ & 15.1 & $6.9-28.7$ & 39.4 & $10.7-100.9$ & 32.0 & $11.7-69.7$ \\
\hline Low back & 14.5 & $7.5-25.4$ & 23.5 & $12.8-39.4$ & 29.6 & $6.1-86.4$ & 21.3 & $5.8-54.6$ \\
\hline
\end{tabular}

a Incidence rate per 100 person-years

Men
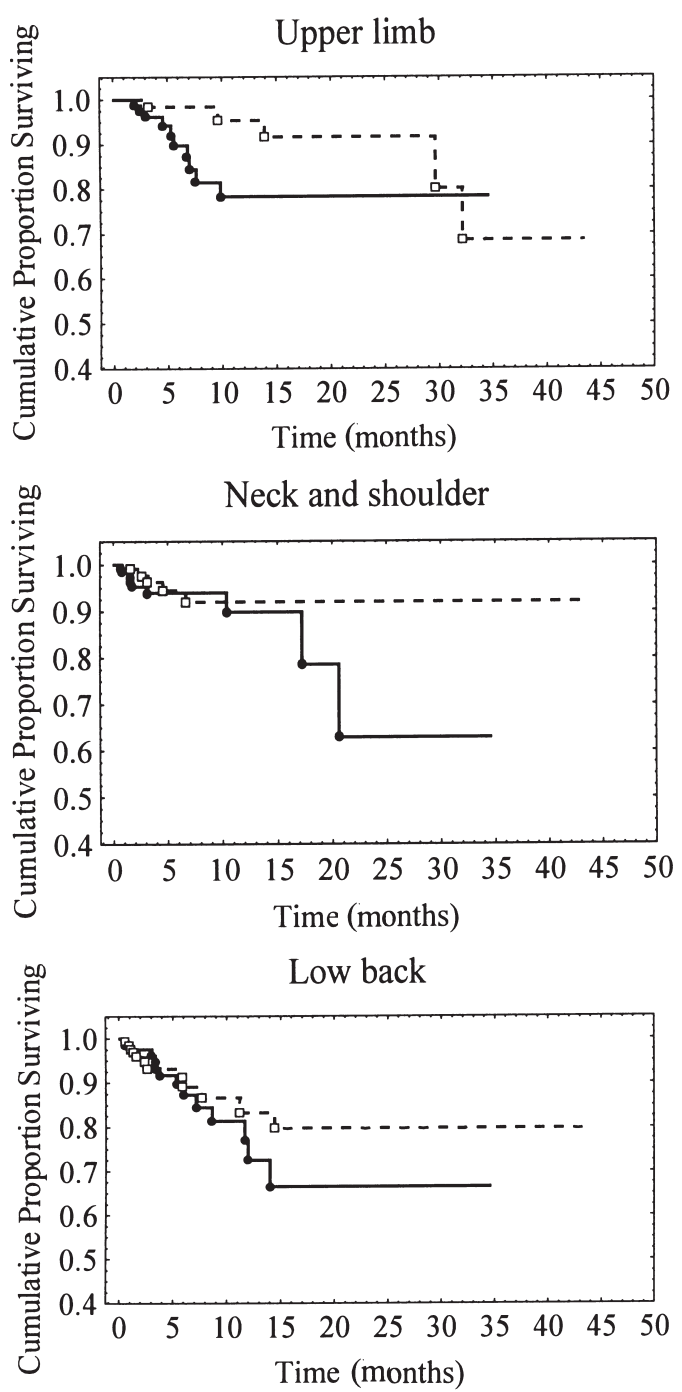

Women
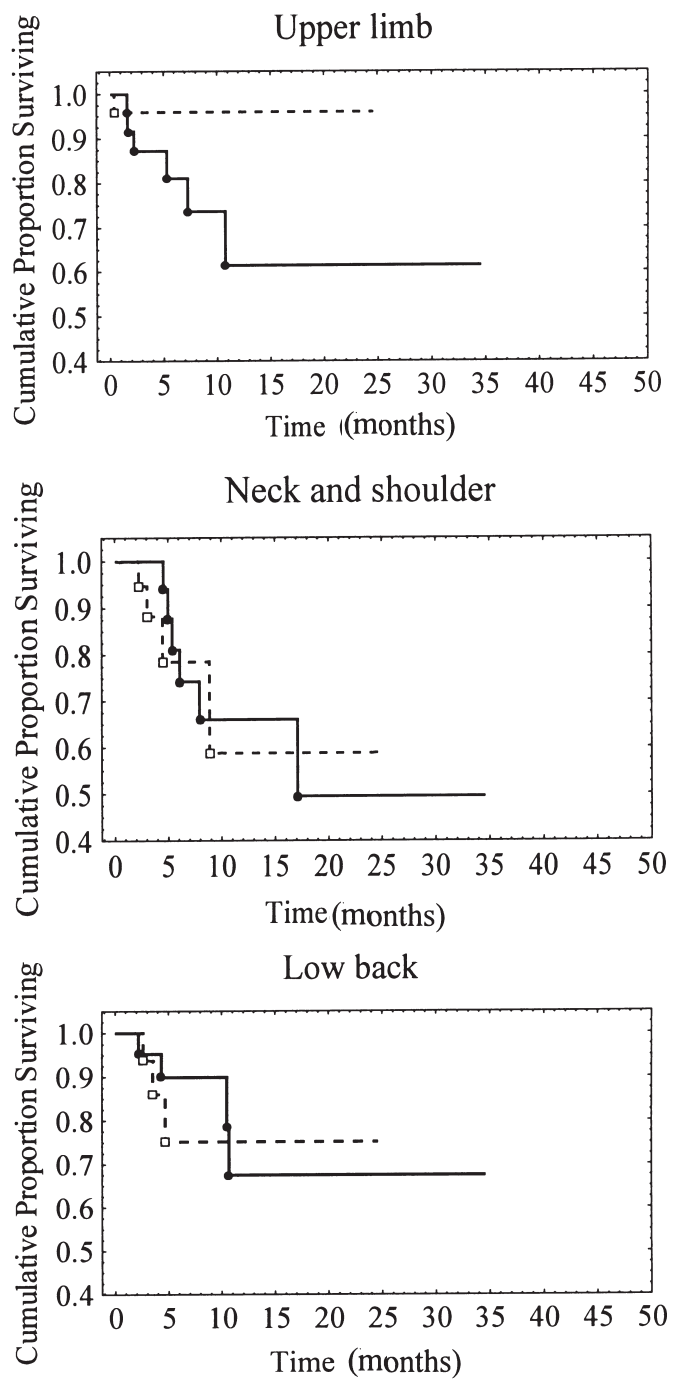

Figure 1. Disease-free survival of the men and women with regard to musculoskeletal disorders. (solid line =high workload, broken line $=$ low workload)

the rate in the high workload group seemed to be about threefold that of the low workload group. Because of the small number of cases and person-years in some of the exposure groups, the differences were not tested statistically.

\section{Survival proportions}

The estimated proportions of workers surviving without upper-limb, neck or shoulder, and low-back disorders are shown in figure 1 . The men with low load tasks had 
a greater chance of surviving without upper-limb disorders than those with high load tasks $(P=0.045)$. At 6 months the estimated proportion of male workers surviving without upper-limb disorders in the high workload group was $90 \%$ [ $95 \%$ confidence interval $(95 \%$ CI) $82-98 \%$ ], and in the low load group it was $98 \%(95 \%$ CI $95-100 \%$ ). At one year the survival proportions in the high load and low load groups were $78 \%$ (95\% CI 66-91\%) and 95\% (95\% CI 89-100\%), respectively. There were no significant differences in the survival curves between the exposure groups regarding neck and shoulder or low-back disorders among the men.

The proportions of women surviving 6 months in the high load group without an upper-limb, neck or shoulder, or low-back disorder were $81 \%$ (95\% CI 64-98\%), $81 \%$ (95\% CI 62-100\%), and 90\% (95\% CI 77-100\%), respectively. At 1 year the proportions were $61 \%$ (95\% CI $33-89 \%), 66 \%$ (95\% CI $41-91 \%$ ), and $67 \%$ (95\% CI 39-96\%). In the low load group the occurrence of upper-limb disorders was rare. Among both the men and the women, most musculoskeletal disorders occurred within the first year.

\section{Predictors of incident disorders}

The men's risk of contracting an upper-limb disorder in the high workload group was over threefold that of the low load group (table 3). Age seemed also to have an independent effect on sick leave due to upper-limb disorders, the risk being the highest in the age group of 25 to 34 years. The men in the high workload group had an almost threefold greater risk of neck and shoulder disorders than that of those in the low load group [hazard ratio (HR) 2.7 (95\% CI 0.9-8.1)], whereas only a slightly elevated risk, though not significant, was observed for low-back disorders. Among the women the unadjusted hazard ratio for high versus low workload was 3.2 (95\% CI 0.4-27.0) for upper-limb disorders, 0.9 (95\% CI 0.2-3.0) for neck and shoulder disorders, and 0.7 (95\% CI 0.2-3.2) for low-back disorders.

\section{Duration of sick leave}

Among the men, the length of the first sick leave was in general similar in the high and low workload groups for almost all anatomical areas (table 4). However, the sick leaves due to upper-limb disorders in the low workload group were longer than those due to the other disorders. The women's first sick leaves were longer for all anatomical areas than those of the men were. The duration of the sick leaves due to upper-limb disorders was independent of the diagnosis.

Table 3. Hazard ratios and $95 \%$ confidence intervals $(95 \% \mathrm{Cl})$ for the predictors of musculoskeletal disorders among newly employed men in assembly work - Cox proportional hazards model.

\begin{tabular}{lcc}
\hline Predictor & Hazard ratio & $95 \% \mathrm{Cl}$ \\
\hline Upper-limb disorders & & \\
Age & & \\
$\quad<25$ years & 1.0 & \\
$25-34$ years & 3.0 & $1.0-9.3$ \\
$\quad>35$ years & 1.4 & $0.3-7.4$ \\
Work load & & \\
$\quad$ Low & 1.0 & \\
$\quad$ High & 3.2 & $1.1-9.4$ \\
Neck and shoulder disorders & & \\
Age & & \\
$\quad<25$ years & 1.0 & \\
$25-34$ years & 1.8 & $0.6-5.8$ \\
$>35$ years & 1.2 & $0.2-5.8$ \\
Work load & & \\
Low & 1.0 & $0.9-8.1$ \\
High & 2.7 & \\
Low-back disorders & & \\
Age & & \\
$\quad<25$ years & 1.0 & $0.4-2.1$ \\
$25-34$ years & 0.9 & $0.2-2.2$ \\
$\quad>35$ years & 0.6 & \\
Work load & & \\
Low & 1.0 & \\
High & 1.5 & \\
\hline
\end{tabular}

Table 4. Duration of sick leave for the first occurrence of a musculoskeletal disorder by gender and workload during the follow-up. (N= number of subjects on sick leave, Q1-Q3 = lower and upper quartiles)

\begin{tabular}{|c|c|c|c|c|c|c|c|c|c|c|c|c|}
\hline \multirow[t]{3}{*}{ Region of disorder } & \multicolumn{6}{|c|}{ Men } & \multicolumn{6}{|c|}{ Women } \\
\hline & \multicolumn{3}{|c|}{ Low load } & \multicolumn{3}{|c|}{ High load } & \multicolumn{3}{|c|}{ Low load } & \multicolumn{3}{|c|}{ High load } \\
\hline & $\mathrm{N}$ & $\begin{array}{l}\text { Median } \\
\text { (days) }\end{array}$ & Q1-Q3 & $N$ & $\begin{array}{l}\text { Median } \\
\text { (days) }\end{array}$ & Q1-Q3 & $\mathrm{N}$ & $\begin{array}{l}\text { Median } \\
\text { (days) }\end{array}$ & Q1-Q3 & $\mathrm{N}$ & $\begin{array}{l}\text { Median } \\
\text { (days) }\end{array}$ & Q1-Q3 \\
\hline $\begin{array}{l}\text { Upper limb } \\
\text { Neck and shoulder } \\
\text { Low back }\end{array}$ & $\begin{array}{r}5 \\
5 \\
12\end{array}$ & $\begin{array}{l}8.0 \\
4.0 \\
4.0\end{array}$ & $\begin{array}{l}8.0-9.0 \\
3.0-8.0 \\
3.0-6.0\end{array}$ & $\begin{array}{r}10 \\
9 \\
14\end{array}$ & $\begin{array}{l}4.5 \\
5.0 \\
5.5\end{array}$ & $\begin{array}{l}4.0-7.0 \\
2.0-6.0 \\
4.0-8.0\end{array}$ & $\begin{array}{l}. \\
4 \\
3\end{array}$ & $\begin{array}{r}8.0 \\
11.0\end{array}$ & $\begin{array}{l}2.5-15.5 \\
5.0-17.0\end{array}$ & $\begin{array}{l}6 \\
6 \\
4\end{array}$ & $\begin{array}{r}9.0 \\
6.0 \\
12.5\end{array}$ & $\begin{array}{l}7.0-17.0 \\
5.0-16.0 \\
7.0-16.5\end{array}$ \\
\hline
\end{tabular}




\section{Discussion}

This study showed that physical load factors had a major role in the development of incident neck-shoulder and upper-limb disorders. The men with a high workload had about a threefold risk of upper-limb and neck and shoulder disorders in comparison with those with a low workload. In the high load tasks several generic physical load factors, such as repetitiveness, high force demands, and wrist postures, were all present, whereas in the low load tasks there were only a few, if any, such factors.

The risk of low-back disorders did not differ markedly between the high and low workload group. Even though some tasks with a high workload consisted of multiple lifting and working postures with a forward flexed trunk, there was a less distinct contrast in the physical load factors with regard to the low back in the high and low workload groups.

The high load tasks were classified as strenuous for all body parts. While the criterion for high load required the existence of at least two load factors for each body region, in low load tasks the presence of one load factor was possible. This was the case in, for example, forklift driving, which included static neck posture for $>2$ hours per day, but in lack of other load factors, was classified as a low load task for the neck. The fact that the low load tasks were not completely free of load factors decreased the contrast between high and low workloads.

Those with strenuous tasks sought medical advice because of upper-limb disorders typically some months after starting their work, and most upper-limb disorders occurred within the first year among both the men and the women. This finding suggests that these disorders require a fairly long induction time and latency to be manifest as clinical disease. Yet our end point was seeking medical advice, and the workers may have had symptoms earlier. In an analysis of clinical cases of epicondylitis a typical onset was reported to be insidious (9). - Another explanation for the relatively long induction time could be unwillingness to seek medical care during the probation period. No increase in the incidence rates of sick leave after the probation was found, however.

There may have been a difference in seeking medical advice between the high and low workload groups. Those in the high workload group may not have been able to perform their tasks due to their symptoms, whereas those with a low load could have continued despite of their disorders. This behavior could have caused bias by inflating the risk estimates for the high load group (10).

There are very little data on the incidence of musculoskeletal disorders. A Finnish study by Kurppa et al (10) on meat-processing workers from a time period about 5 years earlier than ours showed an incidence density of 16.2 per 100 person-years for upper-limb disorders among men and 30.3 among women. Incidence density in their study, considering recurrent episodes of one worker as distinct occurrences, resulted in higher values than the incidence of first occurrence in our study. Our values therefore suggest a somewhat higher occurrence than theirs in reality, although the estimates from the two studies seem almost equal. In Washington State the incidence rate of upper-extremity disorders was 1.16 per 100 person-years (epicondylitis 0.11 , carpal tunnel syndrome 0.24) in 1990 through 1998 according to accepted worker compensation claims (11).

Our findings concerning the induction times are well in line with the results of earlier studies. Westgaard \& Aarås (2) reported the first occurrences of musculoskeletal disorders as early as 3-6 months after the beginning of employment in an electromechanical plant in tasks requiring a high level of muscle load. A followup study of sewing machine operators showed that a large number of young operators had their first sick leave due to musculoskeletal disorders within a few months of employment (3). In a study on chocolate packers, in which workers were interviewed and examined at 10-week intervals, the median time period in the development of patient status was about 6 months (4). On the other hand, nerve conduction measurements showed a prolongation of median nerve motor and sensory nerve latency occurring within 2 months after the beginning of employment in hand-intensive tasks in the pork processing industry (12). An experimental study on upper-extremity disorders in rats showed inflammatory changes in muscle, tendon, and ligament in as few as 3 weeks in tasks with high repetition and negligible force (13).

The median of the duration for the first sick leave for a upper-limb disorder (consisting primarily of tenosynovitis-peritendinitis and epicondylitis) was found to range from 4.5 to 9 days. In the study by Kurppa et al (10) the median of the duration of tenosynovitis and epicondylitis was reported to be 10 days, and that of epicondylitis was 16 days. The longer durations in their study are partly due to their definition of disease episode, according to which sick leaves within 60 days were considered to be due to one episode. In another Finnish study the median duration of a sick leave due to epicondylitis was 14.4 days (14). In a study exploring labor statistics in the United States the median days lost for upper-extremity disorders such as tendinitis, tenosynovitis, and bursitis have been reported to be 10 to 13 (15).

The first sick leaves due to upper-limb disorders among the men in the low load group of our study were longer than those in the high load group. While no differences in duration were observed between the sick 
leaves due to different diagnoses, the longer duration may have been associated with the possible development of more severe disorders with increasing exposure time. Among the men in the low load group the first upperlimb disorders developed later than those in the high load group.

The major limitation of our study was the small number of cases and person-years within the exposure groups. Although we had a fairly large group of workers entering our population during the follow-up period, the turnover rate was high, and therefore the exposure time for individual workers was short. A comparison of the sick leave rates of different exposure groups revealed that the turnover was independent of both the workload category and the rate of sick leave (5). However, health-based selection is difficult to rule out completely. We therefore believe that our risk estimates may be lower than they would have been in a situation with a low turnover rate. - Another limitation of the study was the small number of women.

The strength of the study is the relatively large population of new workers free of musculoskeletal disorders at the onset of the study. Furthermore, the majority had no previous exposure to similar types of assembly work. All the diagnoses were made and sick leaves prescribed by the same physician throughout the study, and therefore the data can be considered consistent over time.

In conclusion, this study indicates that newly employed workers in hand-intensive tasks have a high risk of upper-limb and neck-shoulder disorders. The results of this prospective study suggest an etiologic role for activities involving high force demands in upper-limb and neck-shoulder disorders. This result points to the importance of primary preventive actions aimed at newly employed or unaccustomed workers. Such measures could consist of engineering and administrative controls, making new workers accustomed to strenuous tasks gradually, and the surveillance of early symptoms.

\section{References}

1. Panel on Musculoskeletal Disorders and the Workplace, Commission on Behavioral and Social Sciences and Education, National Research Council and the Institute of Medi- cine. Musculoskeletal disorders and the workplace: low back and upper extremitites. Washington, DC: National Academy Press, 2001.

2. Westgaard RH, Aarås A. Postural muscle strain as a causal factor in the development of musculo-skeletal illnesses. Appl Ergon 1984;15(3):162-74.

3. Wærsted M, Westgaard RH. Working hours as risk factor in the development of musculoskeletal complaints. Ergonomics 1991;34(3):265-76.

4. Veiersted KB, Westgaard RH. Development of trapezius myalgia among female workers performing light manual work. Scand J Work Environ Health 1993;19(4):277-83.

5. Häkkänen M, Viikari-Juntura E, Martikainen R. Job experience, work load, and risk of musculoskeletal disorders. Occup Environ Med 2001;58(2):129-35.

6. Viikari-Juntura E. Neck and upper limb disorders among slaughterhouse workers: an epidemiologic and clinical study. Scand J Work Environ Health 1983;9:283-90.

7. Kalbfleisch JD, Prentice RL. Statistical analysis of failure time data. New York (NY): John Wiley \& Sons Inc, 1980.

8. Lee ET. Statistical methods for survival data analysis. Belmont (CA): Lifetime Learning, 1980.

9. Viikari-Juntura E, Kurppa K, Kuosma E, Huuskonen M, Kuorinka I, Ketola R, et al. Prevalence of epicondylitis and elbow pain in the meat-processing industry. Scand J Work Environ Health 1991;17(1):38-45.

10. Kurppa K, Viikari Juntura E, Kuosma E, Huuskonen M, Kivi $\mathrm{P}$. Incidence of tenosynovitis or peritendinitis and epicondylitis in a meat-processing factory. Scand J Work Environ Health 1991;17(1):32-7.

11. Silverstein B, Viikari-Juntura E, Kalat J. Work-related musculoskeletal disorders of the neck, back, and upper extremity in Washington State, 1990-1998. Olympia (WA): Safety \& Health Assessment \& Research for Prevention (SHARP), 2000. Technical report number 40-4a-2000.

12. Kearns J, Gresch EE, Weichel CY, Eby P, Pallapothu SR. Pre- and post-employment median nerve latency in pork processing employees. J Occup Environ Med 2000;42(1):96100.

13. Barr AE, Safadi FF, Garvin RP, Popoff SN, Barbe MF. Proceedings of the IEA/HFES 2000 Congress. In: XIVth triennal congress of the international association and 44th annual meeting of the Human Factors and Ergonomics Society "Ergonomics for the New Millenium". San Diego (CA): Human Factors and Ergonomics Society, 2000:5-584-7.

14. Kivi P. The etiology and conservative treatment of humeral epicondylitis. Scand J Rehabil Med 1983;15:37-41.

15. Hashemi L, Webster BS, Clancy EA, Courtney TK. Length of disability and cost of work-related musculoskeletal disorders of the upper extremity. J Occup Environ Med 1998;40(3):261-9.

Received for publication: 16 May 2001 